\title{
Effect of Abiotic Degradation on the Colorimetric Analysis, Mechanical Properties and Morphology of PLA Composites with Linen Fibers
}

\author{
Aneta Tor-Świątek ${ }^{1 *}$, Tomasz Garbacz ${ }^{1}$ \\ 1 Lublin University of Technology, Faculty of Mechanical Engineering, Department of Technology and Polymer \\ Processing, ul. Nadbystrzycka 36, 20-618 Lublin, Poland \\ *Corresponding author's email: a.tor@pollub.pl
}

\begin{abstract}
The manufacturing of composites from biomaterials enables the production of environment- and user-friendly biodegradable products. The matrix of such composite materials is made of biopolymers such as PLA or PGA, while the reinforcement is usually made of natural fibers. Such composites have unique physical and mechanical properties as well as distinctive, eye-catching performance and aesthetic characteristics such as texture, color or roughness. This paper presents the results of colorimetric examination of polymer-linen biocomposite materials under abiotic degradation. The colorimetric examination was made based on a CIELAB model determining the values of lightness, color saturation, chromatic colors and total color difference. The SEM morphology of the specimen surface fracture was also examined. The obtained results show a significant effect of abiotic degradation on the tested parameters.
\end{abstract}

Keywords: biocomposites, polyactide, flax fiber, thermal degradation, color

\section{INTRODUCTION}

Polyactide (PLA) is one of the most important, totally biodegradable polymers. Polylactide (PLA) is a polyester derived from lactic acid that has been the main biodegradable polymer used in biomedical research and applications for the past five decades. As a bioabsorbable polymer, PLA, is one of the most promising biopolymers due to the fact that the monomers may be produced from non-toxic renewable feedstock as well as due to being a naturally occurring organic acid $[7,16]$. It is also a leading biomaterial for numerous applications in medicine, as well as in industry, replacing conventional petrochemical-based polymers [16]. It comprises almost $40 \%$ of all biodegradable plastics. The period of biodegradability of synthetic polymers such as PE or PS ranges from 500 to 1000 years, while that of PLA ranges between six months and two years [5, 9, 27].
In comparison to other biopolymers, the PLA has numerous advantages, like [7, 17, 21, 23]:

a) Eco-friendliness - apart from being derived from renewable resources (e.g., corn, wheat, or rice);

b) Biocompatibility - especially with respect to biomedical applications. A biocompatible material should not produce toxic or carcinogenic effects in local tissues;

c) Biodegradability - PLA is biodegradable, recyclable, and compostable. The PLA degradation products are non-toxic (at a lower composition) making it a natural choice for biomedical applications;

d) Processibility - PLA has better thermal processibility compared to other biopolymers such as poly(hydroxyl alkanoate)(PHA), poly(ethylene glycol) (PEG) and poly ( $\gamma$-caprolactone) (PCL). It can be processed by injection molding, film extrusion, blow molding, thermoforming, fiber 
spinning, and film forming;

e) Energy savings - PLA requires $25-55 \%$ less energy to produce than petroleum-based polymers and estimations show that this can be further reduced to less than $10 \%$ in the future.

PLA generally come in the form of granulates, and they are processed for the production of films, fibers, plastic containers, and other commodity products [23]. These materials are also used for the $3 \mathrm{~d}$ printing technique $[1,2,6]$.

In order to make it suitable for special applications, PLA is modified by the addition of fillers or preparation of blends $[8,19,22,26]$. These include starch - to decrease the breakdown time of the polymer and reduce the manufacturing costs, and cellulose fibers - to enhance thermal resistance and rigidity. Modifiers can also be made of inorganic nanofillers such as mica, glass, talc. PLA is often reinforced with synthetic fibers, such as glass and carbon fibers. It can also by reinforced with natural fibers, including wood, cotton, flax, sisal, jute and hemp fibers. A combination of natural fibers and PLA produces an environment-friendly biocomposite material which is one-hundred percent renewable [3, 9, 12].

The use of natural fibers as reinforcement for polymer composites has many advantages due to their properties, such as low density, biodegradability, the ease of recyclability, and acoustic damping. Their use can help decrease thermal expansion of the composite matrix. The processing of such composite materials is constrained by the permissible processing temperature which should not exceed $230^{\circ} \mathrm{C}$. If the temperature exceeds $230^{\circ} \mathrm{C}$, fibers start to shrink and break down, which has a negative effect on properties of the composite material. If fibers are subjected to heating, this may cause the physical and/or chemical changes in their structure, such as depolymerization, hydrolysis, oxidation, dehydration, decarboxylation and recrystallization. In order to prevent these defects, it is necessary to restrain/ reduce the temperature range and the processing tome [12, 14, 24].

Linen fiber is made up of bundles containing 10-40 individual fibers with a length of approx. $30 \mathrm{~mm}$ and a diameter of $0.2 \mathrm{~mm}$. These single fibers are bound together and elongated by pectin, forming a $60-90 \mathrm{~cm}$ long bundle. Linen fiber is composed of $65-70 \%$ cellulose, $3-5 \%$ lignin, approx. 15\% hemicellulose and 5-7\% pectin (and up to $5 \%$ phenol, ash, wax). Linen fibers have very high vibration damping properties - their vibration damping ability is two and a half times higher than that of carbon fibers. Long linen fibers have lower tensile properties than short fibers [15, 18, 20, 25].

The shortcomings of natural fibers include their hydrophilic nature, low thermal resistance and a high scatter of mechanical properties. Studies are conducted to develop the solutions for enhancing the fiber strength e.g. by softening or boiling. It is also vital to identify the mechanisms affecting the phase boundaries in polymer-matrix fibrous composites. The adhesion between hydrophilic natural fibers and hydrophobic polymer matrix is very low. Most natural fibers are characterized by porosity, which leads to increased humidity absorption by the fibers and reduced adhesion [12].

In terms of the use of natural materials for consumer products, the key properties are the strength, processability, shape and size stability along with thermal and material stability of these materials. The examination of abiotic degradation of PLA constitutes a method for determining the stability of composite materials $[4,10]$. One of the effects of biomaterial degradation is the change of color components such as the lightness - luminance of a color $\left(\mathrm{L}^{*}\right)$, base color $\left(\mathrm{a}^{*}, \mathrm{~b}^{*}\right)$, total color difference $(\Delta \mathrm{E})$ and saturation $\left(\mathrm{C}^{*}\right)$. Color measurement allows a qualitative analysis of different material types. Color determination can be performed based on the CIELAB color space model, enabling the expression of color via Cartesian and cylindrical coordinates. According to this model, the $\mathrm{L}$ value (ranging from 0 - the darkest black to 100 - the brightest white) is expressed with Cartesian coordinates as [11]:

$$
L=116 * f\left(\frac{Y}{Y_{O}}\right)-16
$$

while $\mathrm{a}^{*}$ and $\mathrm{b}^{*}$ :

$$
\begin{aligned}
& a=500\left(f\left(\frac{X}{X_{O}}\right)-f\left(\frac{Y}{Y_{O}}\right)\right) \\
& b=200\left(f\left(\frac{Y}{Y_{O}}\right)-f\left(\frac{Z}{Z_{O}}\right)\right)
\end{aligned}
$$

where: $X, Y, Z$ denote the trichromatic color components obtained by the transformation of the components

$R$ - red, $G$ - green, 
$B$ - blue, while $\mathrm{X}_{\mathrm{O}}, \mathrm{Y}_{\mathrm{O}}, \mathrm{Z}_{\mathrm{O}}$ are the component of white light used as a reference color.

For the equations above, the function $f(t)$ is defined with [11]:

$$
f(t)=\left\{\begin{aligned}
\sqrt[3]{t}, & t>0,008856 \\
\frac{903,3 t+16}{116}, & t \leq 0,008856
\end{aligned}\right.
$$

where the functions $\mathrm{f}_{\mathrm{X}}, \mathrm{f}_{\mathrm{Y}}, \mathrm{f}_{\mathrm{Z}}$ are expressed as:

$$
\begin{gathered}
f_{X}=\frac{a}{500}+f_{Y} \\
f_{Z}=f_{Y}-\frac{b}{200} \\
f(y)\left\{\begin{array}{cc}
\frac{L+16}{116}, & y_{0}>0,008856 \\
\frac{903,3 y_{0}+16}{116}, & y_{0} \leq 0,008856
\end{array}\right.
\end{gathered}
$$

In the CIELAB model, the saturation $\mathrm{C}$ and the total color difference $\Delta \mathrm{E}$ are respectively expressed as [11]:

$$
\begin{gathered}
c=13 L \sqrt{\left(a-a_{O}\right)^{2}+\left(b-b_{O}\right)^{2}} \\
\Delta E=\sqrt{\left(L_{2}-L_{1}\right)^{2}+\left(a_{2}-a_{1}\right)^{2}+\left(b_{2}-b_{1}\right)^{2}}
\end{gathered}
$$

The condition of objects made from a given material essentially depends on their physical properties, primarily their mechanical strength and color. For this reason, the decrease in total color difference of the specimens induced by ageing is one of the basic parameters describing the life of a given material under specified storage or exposure conditions. For many polymeric materials and low molecular compounds, the changes in molecular structure caused by the impact of various destructive factors (e.g. heat, UV radiation) are reflected in the change of their color [24].

The objective of this study was to investigate whether the colorimetric, mechanical properties and morphology examination can be used for assessing the degree of degradation of polymeric biomaterials.

\section{MATERIALS AND METHODS}

The study was performed on a linen fiber-reinforced composite material with polyactide matrix, produced by injection molding. The composite material was subjected to thermal degradation to investigate its effect on the color and morphology of the composite.

The matrix was made of granulated polyactide, PURAPOL L130. Compared to the standard PLA, it has a higher melting temperature and a higher crystallization rate. Selected properties of this polyactide, as specified by the manufacturer, are listed in Table 1.

The reinforcement was made from long, combed organic linen fibers. In order to obtain short fibers, the long fibers were cut with a cutter to the length ranging from 5 to $10 \mathrm{~mm}$.

Dumbbells (Figure 1) were produced by injection molding with the ARBURG Allrounder $320 \mathrm{C}$ plastic injection molder. The injection molding process was described by the following parameters: the temperatures of individual zones of the plasticizing unit were set equal to $40^{\circ} \mathrm{C}, 150^{\circ} \mathrm{C}, 180^{\circ} \mathrm{C}, 200^{\circ} \mathrm{C}, 200^{\circ} \mathrm{C}$ and $200^{\circ} \mathrm{C}$, respectively; the injection pressure was set equal to $90 \mathrm{MPa}$; the clamp pressure was set equal to $90 \mathrm{MPa}$; the cycle time was set equal to $43.57 \mathrm{~s}$;

Table 1. Selected properties of PURAPOL L130, according to the product data provided by the manufacturer

\begin{tabular}{|l|c|}
\hline \multicolumn{1}{|c|}{ Property, unit } & Value \\
\hline Density, $\mathrm{kg} / \mathrm{m}^{3}$ & 1240 \\
\hline Stereochemical purity, \% L-isomer & $\min .99$ \\
\hline Melt flow index, $\mathrm{g} / 10 \mathrm{~min}$ & 16 \\
\hline Melting temperature, $\mathrm{T}_{\mathrm{m},}{ }^{\circ} \mathrm{C}$ & 175 \\
\hline Glass transition temperature $\mathrm{T}_{\mathrm{g} .}{ }^{\circ} \mathrm{C}$ & $55 \div 60$ \\
\hline Tensile modulus, $\mathrm{MPa}$ & 3500 \\
\hline Tensile strength, $\mathrm{MPa}$ & 50 \\
\hline Elongation at break, $\%$ & $\operatorname{max.~5}$ \\
\hline
\end{tabular}

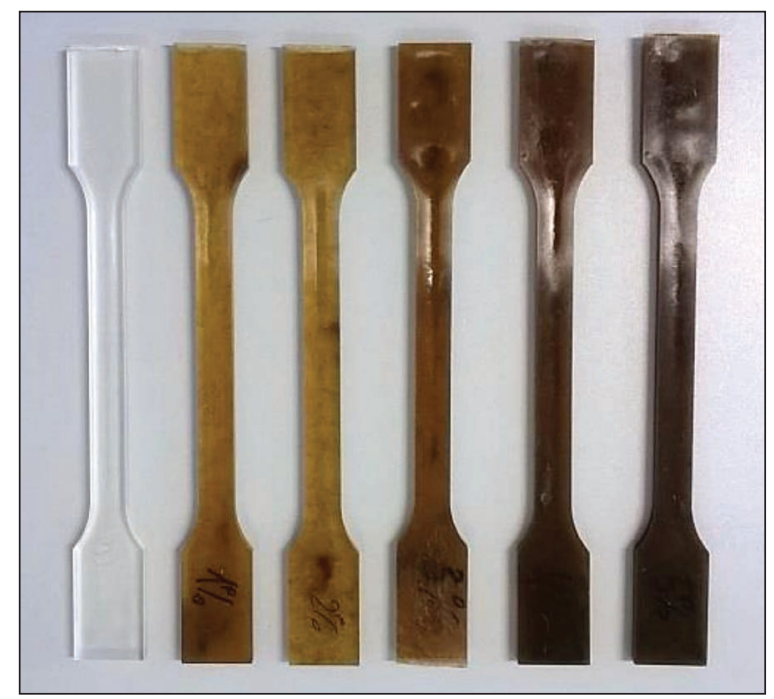

Figure 1. Dumbbell specimens with $0 \%, 1 \%, 2 \%$, $3 \%, 4 \%$ and $5 \%$ linen fiber contents 
the injection time was set equal to $3 \mathrm{~s}$, and the cooling time was set equal to $30 \mathrm{~s}$. As a result of injection molding, moldings were produced with the following linen contents: $0 \%, 1 \%, 2 \%, 3 \%$, $4 \%$ and $5 \%$. During the process, the moldings in the shape of specimens for mechanical testing were obtained. The amount of specimens was 100 pieces, each. Five samples were tested in one test each time, both before and after degradation. The results presented are based on the mean values of five measurements, in accordance with the current subject standards.

The specimens were subjected to thermal degradation for 4 weeks at $60^{\circ} \mathrm{C}$, in compliance with ASTM F1980 - 07:2011. The process parameters were applied in such a way so as to replicate a 12-month degradation at normal temperature. The degradation process was carried out in the SLW 115 TOP + drying oven with the temperature range of $0 \div 300^{\circ} \mathrm{C}$.

The morphology of surface fracture of the specimens after tensile testing was examined with the PHENOM tabletop scanning electron microscope.
The examination of colorimetric analysis of the composite material was conducted with the X-rite Ci4200 benchtop sphere spectrophotometer connected to a desktop computer provided with the Color iControl Ink software. The assessment of color was performed with the use of the CIELAB color space which enables the description of color in Cartesian coordinates. It is based on the following color components: $\mathrm{L}^{*}$ (the lightness component), $a^{*}$ and $b^{*}\left(a^{*}-\right.$ the green-red component, $\mathrm{b}^{*}$ - the blue-yellow component) and $\mathrm{C}^{*}$ (saturation).

The mechanical properties test was conducted with tensile machine Zwick Z010 in compliance with ISO 527:2012.

\section{RESULTS}

\section{Colorimetry}

The examination of color of the polymer-linen composite materials led to obtaining photometric images and spectra profiles, as shown in Figures 2 and 3. The results of the measurement
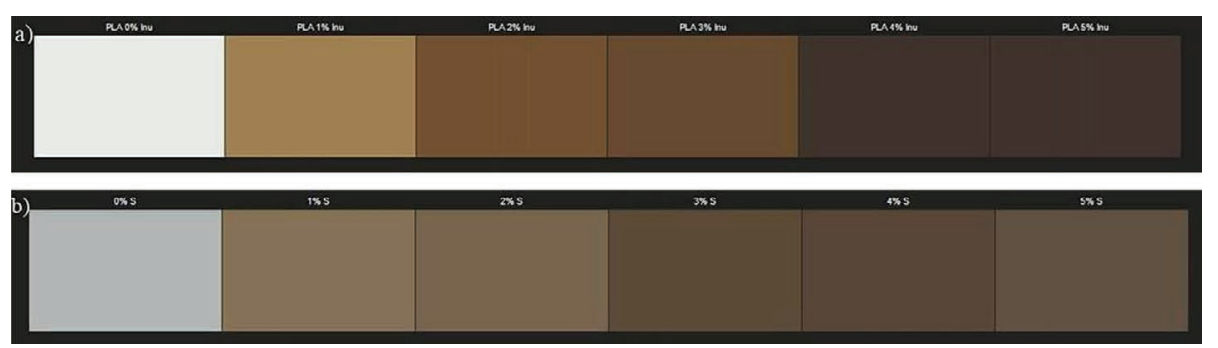

Figure 2. Photometric images of the specimens: a) before degradation b) after degradation
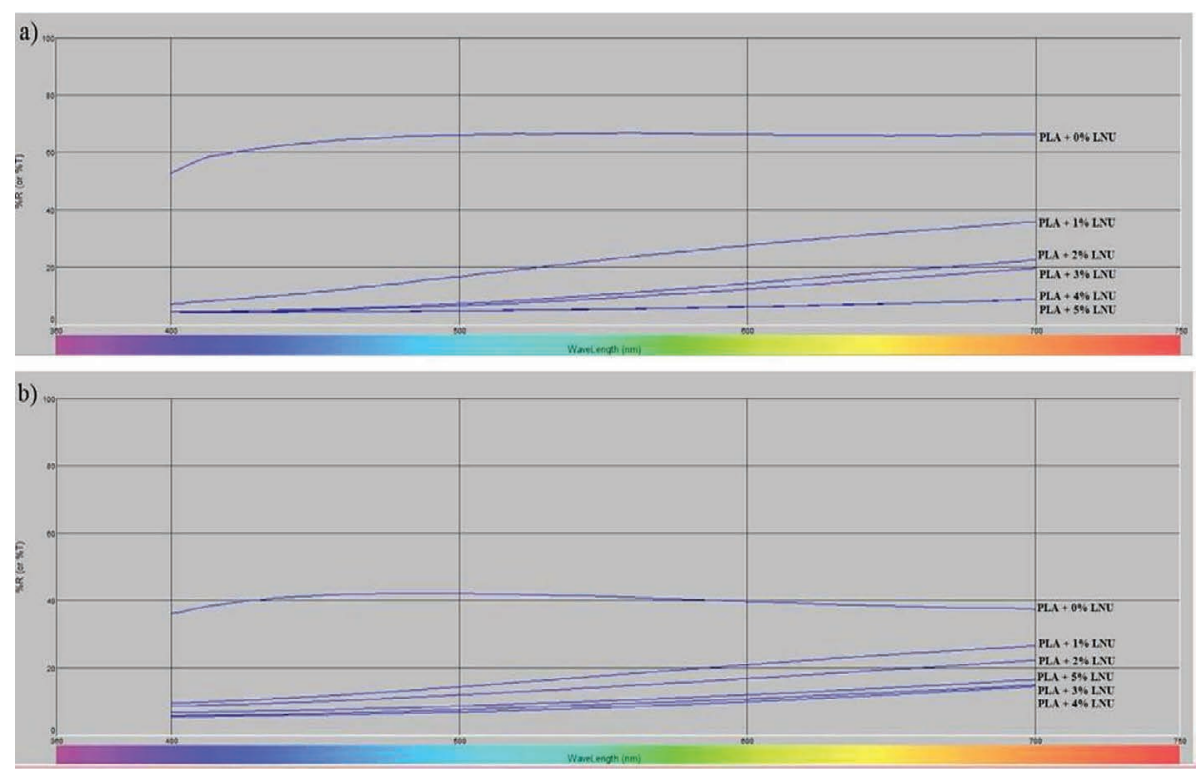

Figure 3. Spectral profiles of the specimens: a) before degradation b) after degradation 
of the CIELAB color space components for the specimens before and after degradation are shown in Figures 4-10.

As a result of degradation, the absorption spectra of the specimens with $0 \%, 1 \%, 2 \%$ and $3 \%$ linen fiber contents decrease proportionally to increasing the linen fiber content. On the other hand, the specimens with $4 \%$ and $5 \%$ linen fiber contents have slightly higher absorption spectra.

The plot illustrating the relationship between the total color difference and the linen fiber content in the specimens before and after degradation (Figure 4) shows that degradation causes the change in color. The greatest change in color resulting from degradation can be observed for the specimens with no linen fiber content, while the smallest for the specimens with $3 \%$ linen fiber content.

The plot of lightness values and linen fiber content of the specimens before and after degradation (Figure 5) shows that, as a result of degradation, the specimens with $0 \%, 1 \%, 2 \%$ and $3 \%$ linen fiber contents become darker, while the specimens with $4 \%$ and 5\% linen fiber contents become lighter. The specimens with $0 \%, 4 \%$ and

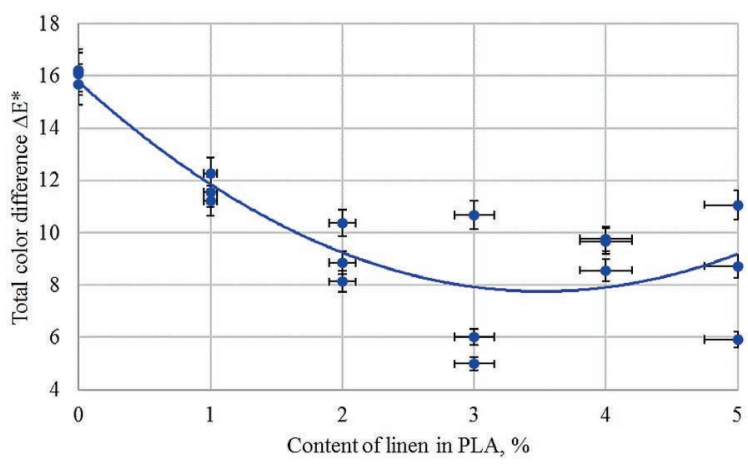

Figure 4. Total color difference versus linen fiber content of the specimens before and after degradation

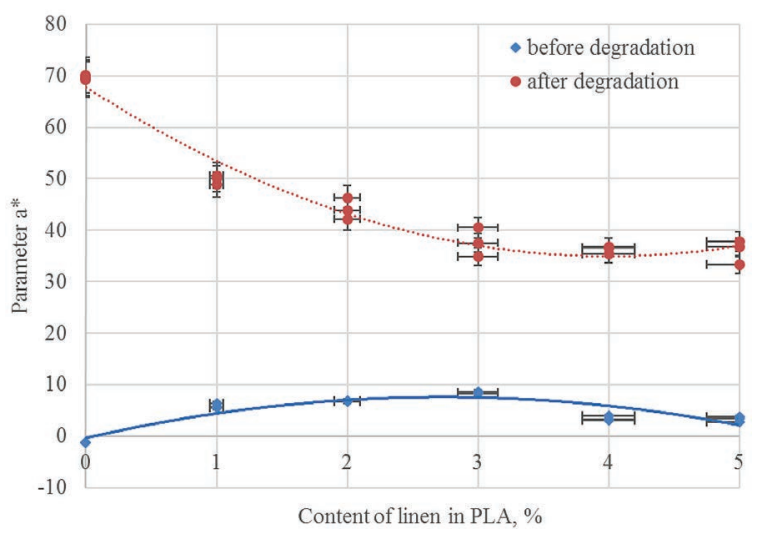

Figure 6. Value $\mathrm{a}^{*}$ versus the linen fiber content in the specimens before and after degradation
$5 \%$ linen fiber contents show significant changes in the lightness value. As a result of degradation, the lightness value of the specimens with no linen fiber content decreases by $18.35 \%$, whereas in the case of the specimens with $4 \%$ and $5 \%$ linen fiber contents, their lightness value increases by $28.66 \%$ and $25.24 \%$, respectively. The specimens with $1 \%, 2 \%$ and $3 \%$ linen fiber contents show slight changes in the lightness value due to degradation, amounting to less than $6 \%$.

In the plot illustrating the relationship between the value $\mathrm{a}^{*}$ and the linen fiber content in the specimens before and after degradation (Figure 6), one can observe that due to the addition of linen fiber, the color of the specimens changes from green to red. As a result of degradation, the value a* decreases for the specimens with $0 \%, 1 \%, 2 \%$ and $3 \%$ linen fiber contents, which means that they become less red; on the other hand, its value increases for the specimens with $4 \%$ and 5\% linen fiber contents, which means that they become redder.

The plot illustrating the relationship between the value $b^{*}$ and the linen fiber content in the specimens before and after degradation (Figure 7) shows

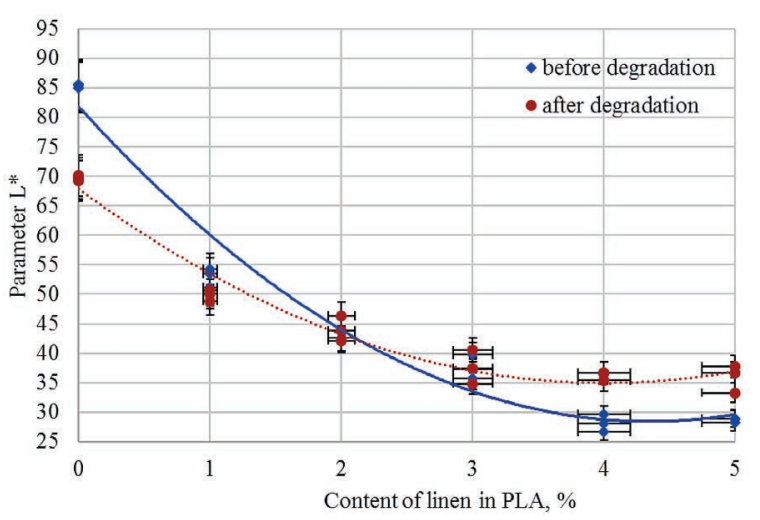

Figure 5. Value L versus the linen fiber content in the specimens before and after degradation

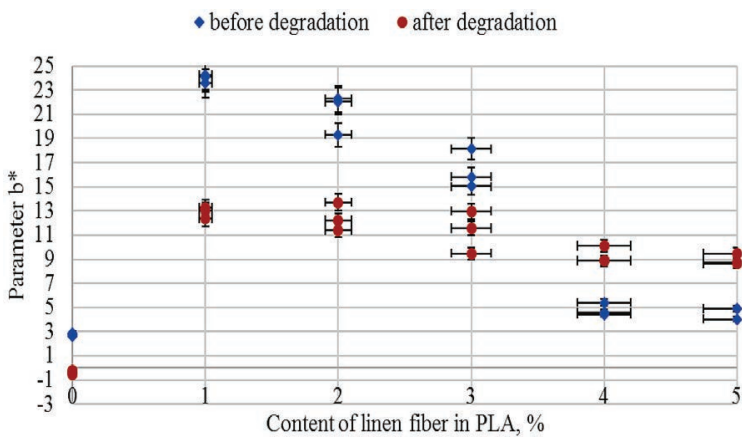

Figure 7. Value $b^{*}$ versus the linen fiber content in the specimens before and after degradation 
that the addition of linen fibers leads to an increase in the value $b^{*}$, which means that the specimens become yellower. As a result of degradation, this parameter decreases for all tested specimens, except for those with $4 \%$ and $5 \%$ linen fiber contents. With decreasing this value, the specimens become less yellow but with its increase the color of the specimens becomes yellower.

The diagram showing the relationship between color saturation and the linen fiber content of the specimens before and after degradation (Figure 8) reveals that the highest color saturation is obtained for the specimens with $1 \%, 2 \%$ and 3\% linen fiber contents. As a result of degradation, the color saturation decreases by approx. $48 \%$ for the specimens with $1 \%$ linen fiber content, by $34 \%$ for the specimens with $2 \%$ linen fiber content, and by $32 \%$ for the specimens with $3 \%$ linen fiber content. The color saturation of the specimens with $4 \%$ and $5 \%$ content of linen fiber is lower prior to degradation than after degradation. Due to degradation, the color saturation of these specimens increases by nearly $37 \%$. The pure polyactide specimen exhibits very low color saturation, the value of which slightly decreases after degradation.

The plots illustrating the relationships between the values $a^{*}$ and $b^{*}$ and the linen fiber content in the specimens (Figures 9 and 10) also demonstrate that prior to degradation, the differences in these values for individual specimens are higher than those observed after degradation when these differences become insignificant. It can therefore be claimed that degradation decreases the differences in color of individual specimens.

\section{Mechanical properties}

The mechanical test was conducted for the samples before and after degradation process. The results of mechanical properties was shown in Table 2. The results shown that abiotic degradation in the assumed degradation parameters, has a slight impact on the measured properties.

For the samples before degradation, the Young's modulus increases by $10 \%$ with the increase of content of linen fibers from $0 \%$ to $5 \%$, while tensile strength and elongation decrease by $19 \%$ and $27 \%$, respectively. For the samples after degradation, the change of the linen fibers content from $0 \%$ to $5 \%$ caused Young's modulus decrease by $4 \%$ and tensile strength increase by $23 \%$ and elongation decrease by $32 \%$.

Abiotic degradation process also caused changes of the measured mechanical parameters in the tested samples. The changes are visible

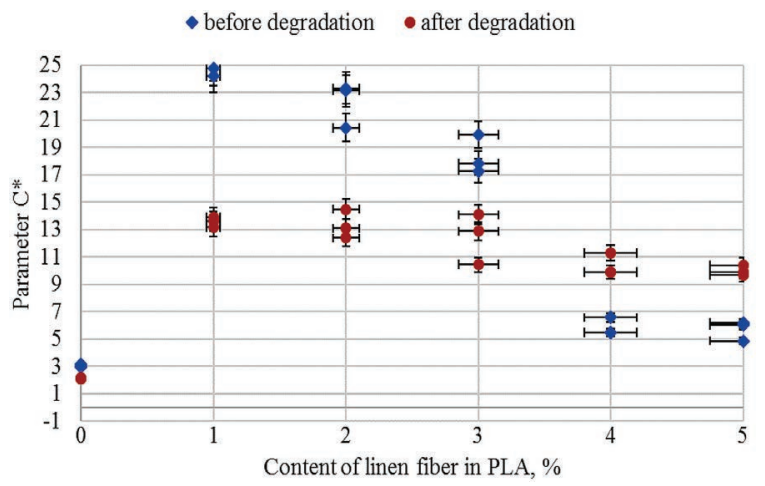

Figure 8. Color saturation versus linen fiber content in the specimens before and after degradation

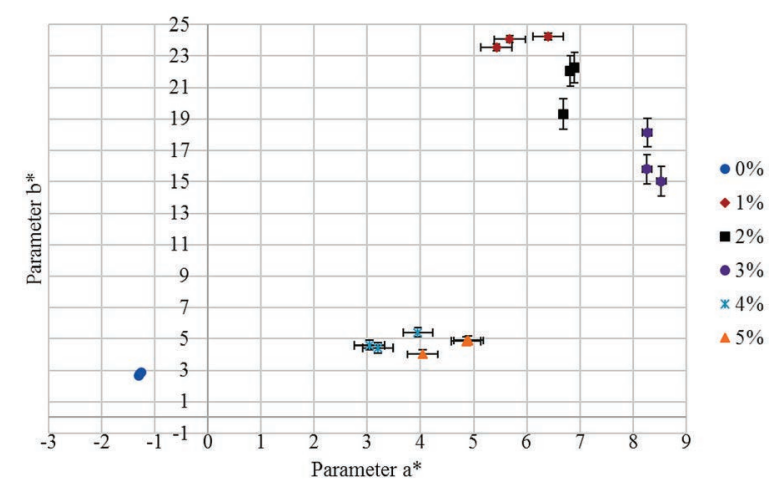

Figure 9. Color saturation versus linen fiber content in the specimens prior to degradation

Table 2. Results of mechanical properties for the samples before and after degradation

\begin{tabular}{|c|c|c|c|c|c|c|}
\hline \multirow[b]{2}{*}{ Materials } & \multicolumn{3}{|c|}{ Results for samples before degradation } & \multicolumn{3}{|c|}{ Results for samples after degradation } \\
\hline & $\begin{array}{c}\mathrm{E}_{\mathrm{t}^{\prime}} \\
\mathrm{MPa}\end{array}$ & $\begin{array}{c}\sigma_{m}, \\
\mathrm{MPa}\end{array}$ & $\begin{array}{c}\varepsilon_{\mathrm{m}}, \\
\% \\
\end{array}$ & $\begin{array}{c}\mathrm{E}_{\mathrm{t}} \\
\mathrm{MPa}\end{array}$ & $\begin{array}{c}\sigma_{\mathrm{m}}, \\
\mathrm{MPa}\end{array}$ & $\begin{array}{c}\varepsilon_{m}, \\
\% \\
\end{array}$ \\
\hline PLA $+0 \%$ linen fibers & 2568.00 & 66.19 & 3.51 & 2537.21 & 71.63 & 3.56 \\
\hline PLA $+1 \%$ linen fibers & 2575.94 & 62.73 & 3.34 & 2619.35 & 68.18 & 3.39 \\
\hline PLA $+2 \%$ linen fibers & 2642.39 & 62.82 & 3.31 & 2618.53 & 66.41 & 3.28 \\
\hline PLA $+3 \%$ linen fibers & 2708.80 & 61.12 & 3.22 & 2651.33 & 61.75 & 2.98 \\
\hline PLA $+4 \%$ linen fibers & 2722.89 & 54.03 & 2.74 & 2603.39 & 53.41 & 2.42 \\
\hline PLA $+5 \%$ linen fibers & 2836.75 & 53.42 & 2.53 & 2642.60 & 54.71 & 2.42 \\
\hline
\end{tabular}




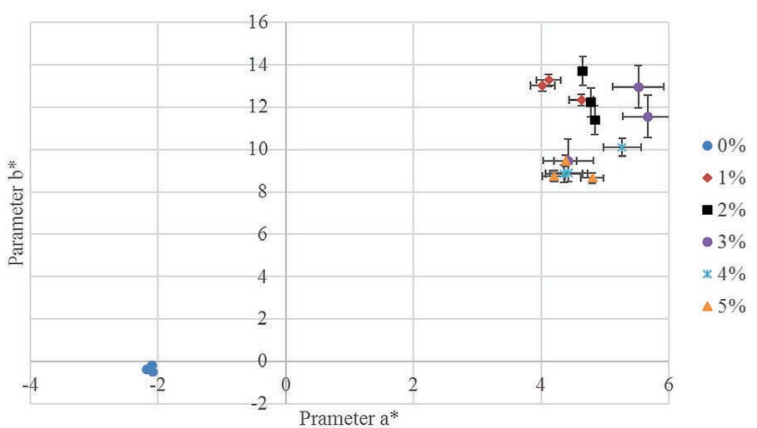

Figure 10. Color saturation versus linen fiber content after degradation

especially for the measures of Young's modulus and elongation in samples with $3 \%$ and greater linen fibers content. The average value these changes is $5 \%$ for Young's modulus and $7 \%$ for elongation. For lower contents of linen fibers (from 0 to $2 \%$ ) the tensile strength value slightly increases due to degradation. Above 3\% of linen fibers, these values are close to the results before degradation. This may be due to the reinforcing effect of the fibers themselves that have not yet degraded, which is related to the supermolecular structure of the moldings obtained. At lower enhancement contents, the fibers were distributed homogeneously and were only in the core of the sample. With higher contents of linen fibers, agglomerations of fibers located in the outer layer of the sample were visible. As a result of the temperature, PLA was degraded, and the linen fibers were partially stripped of the warp, which was visible in the sample with a higher fiber content.

\section{Morphology SEM}

Figures 11-16 compare the morphology of surface fracture caused by tensile testing in the specimens before and after degradation.

The morphology examination reveals that the specimens undergo brittle fracture. The SEM image of the fracture surface of the solid specimen that was not subjected to degradation shows the presence of more extensive and more jagged fragments caused by the specimen rupture. The SEM image of the surface fracture of the specimen after degradation is free from such fragments (Figure 11).

In addition to that, one can observe a separation of the fiber surface from the matrix (Figures 12 and 13), which indicates weak adhesion between the fibers and the polymer matrix. The fiber surface damage of the specimens after degradation is more visible than that of the specimens prior to
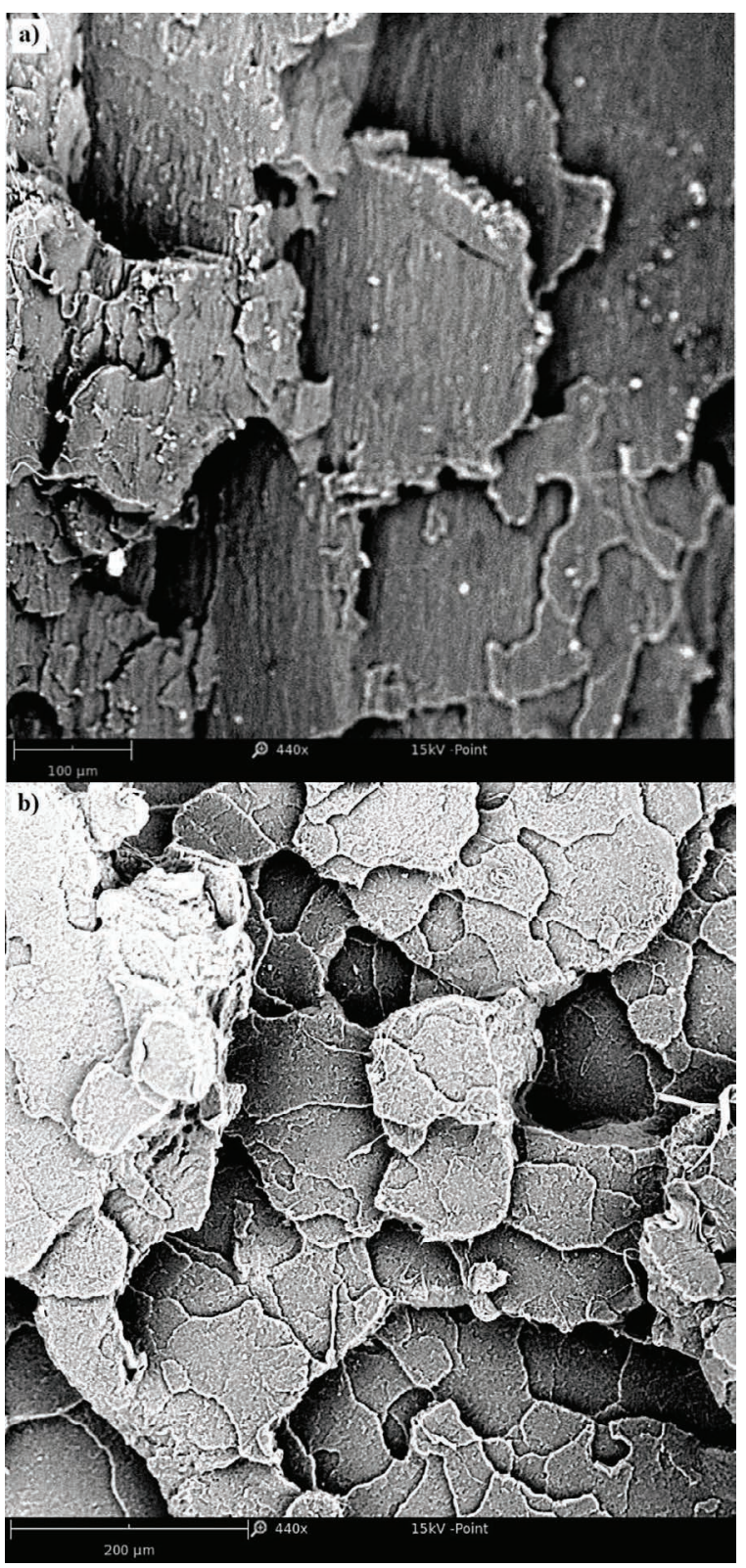

Figure 11. Morphology of the specimen with $0 \%$ linen fiber content: a) before degradation b) after degradation

degradation. One can also observe that the presence of linen fiber prevents crack propagation.

The nature of fiber rupture is shown in Figures 14 and 15 . The specimens subjected to ageing show a more damaged surface of the fibers. In the SEM images of the specimens that were not subjected to ageing, one can see visible empty spaces resulting from the slippage of individual fibers.

Figure 16 reveals a considerable volume fraction of the fibers. One can observe the holes created due to the slippage of individual fibers, which points to weak fiber-matrix adhesion. One can clearly see the change in the matrix structure due to degradation. 

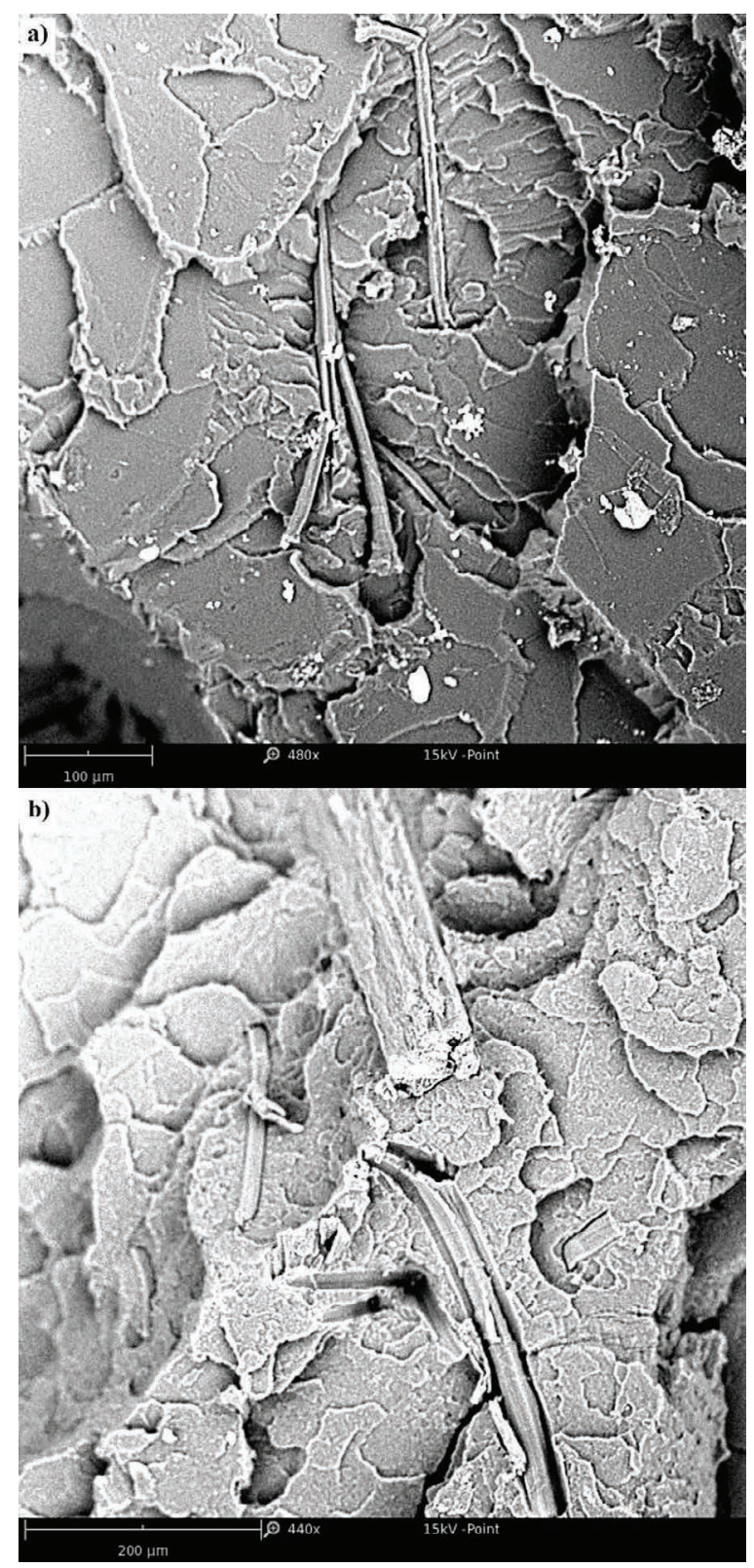

Figure 12. Morphology of the specimen with $1 \%$ linen fiber content: a) before degradation b) after degradation

\section{CONCLUSIONS}

Polymers are widely used in the industry, which poses a problem regarding their waste management. The objectives of this study was to recognition about the characteristics of a fully biodegradable composite and to investigate whether the use of natural materials as composite reinforcement can accelerate the process of their degradation.

The structural analysis has revealed significant changes of the composite morphology due to the increase in the linen fiber content and
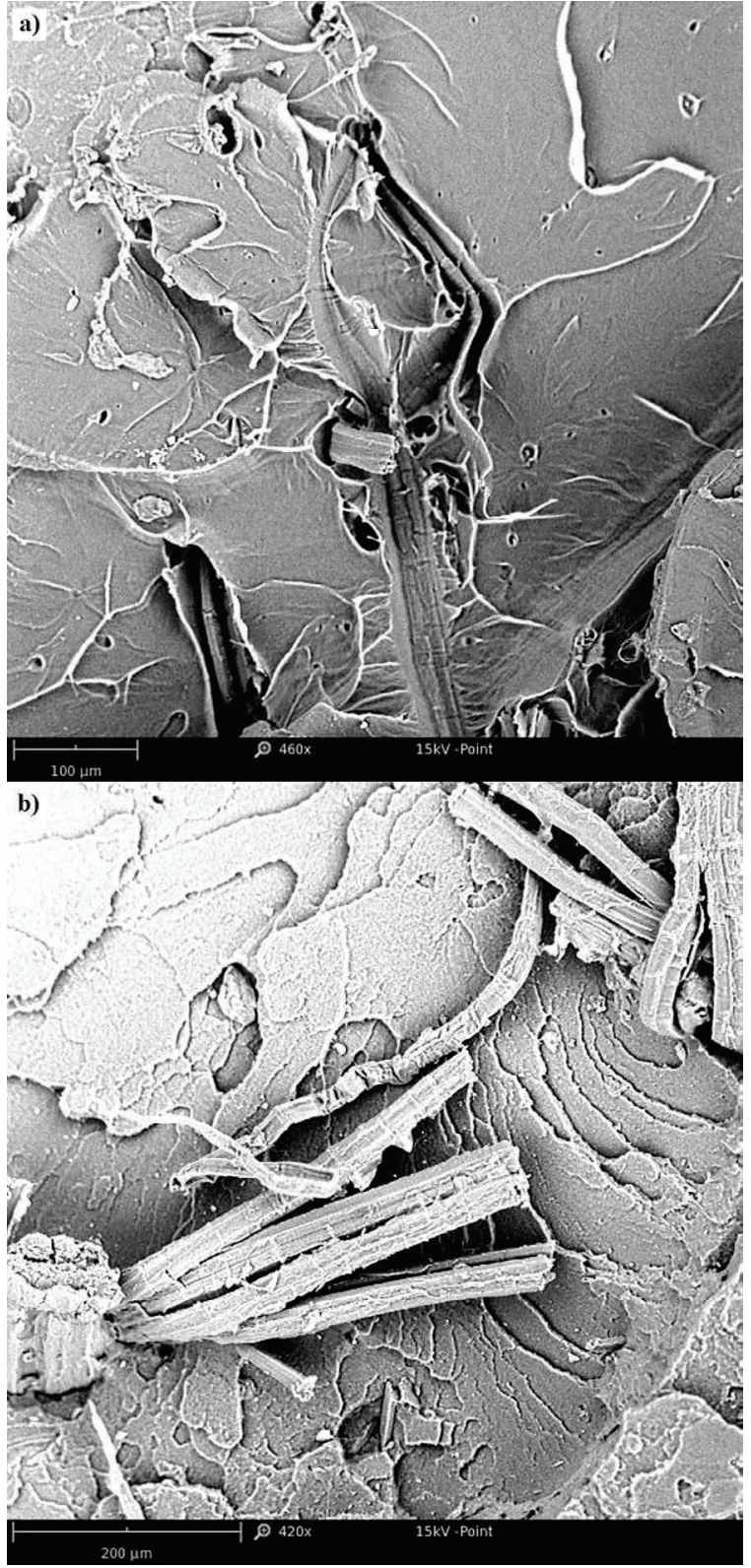

Figure 13. Morphology of the specimen with 2\% linen fiber content: a) before degradation b) after degradation

degradation. The microscopic image analysis showed fiber agglomeration for the samples containing 3-5\% linen fibers. As a result of degradation, the fibers were torn and fragmented, and the agglomeration areas decreased.

The spectrometric analysis results have demonstrated a significant change in color of the test specimens. The observed changes in the color and morphology of the polyactide-matrix composite reinforced with linen fiber indicate the onset of degradation processes, which is reflected in the changes in the composite structure and the start of decomposition of the material. 


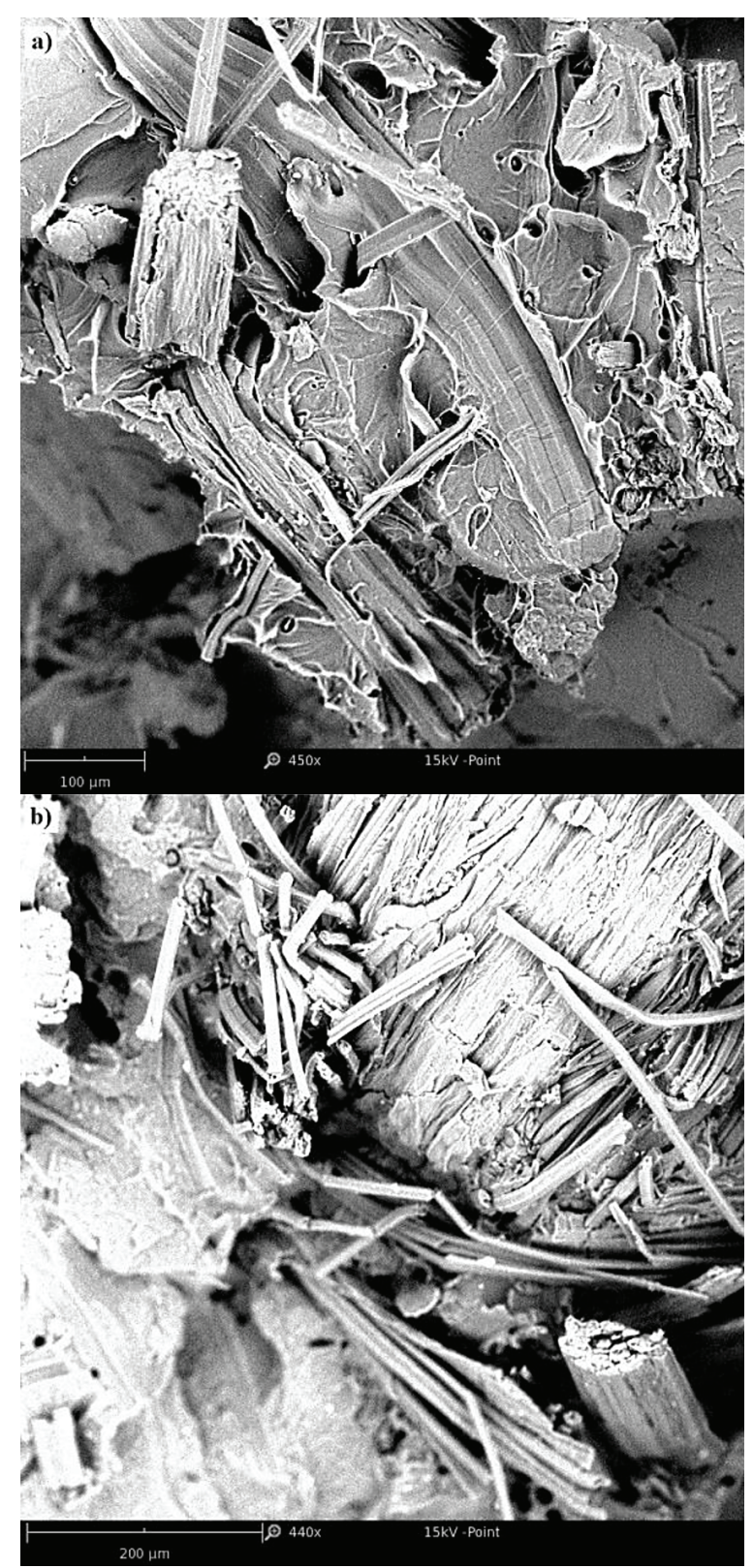

Figure 14. Morphology of the specimen with 3\% linen fiber content: a) before degradation b) after degradation

The tests of mechanical properties showed that the addition of linen fibers increases the stiffness of the composite (Young modulus). Higher stiffness for samples containing linen fibers is observed both before and after degradation. The other tested values, i.e. tensile strength and elongation at break, decreased with increasing content of linen fibers. This may be due to the uneven distribution of fibers in the measuring part of the sample. There is a higher concentration of fibers in the gripping part of the samples. In summary, adding natural fibers to PLA made it possible to

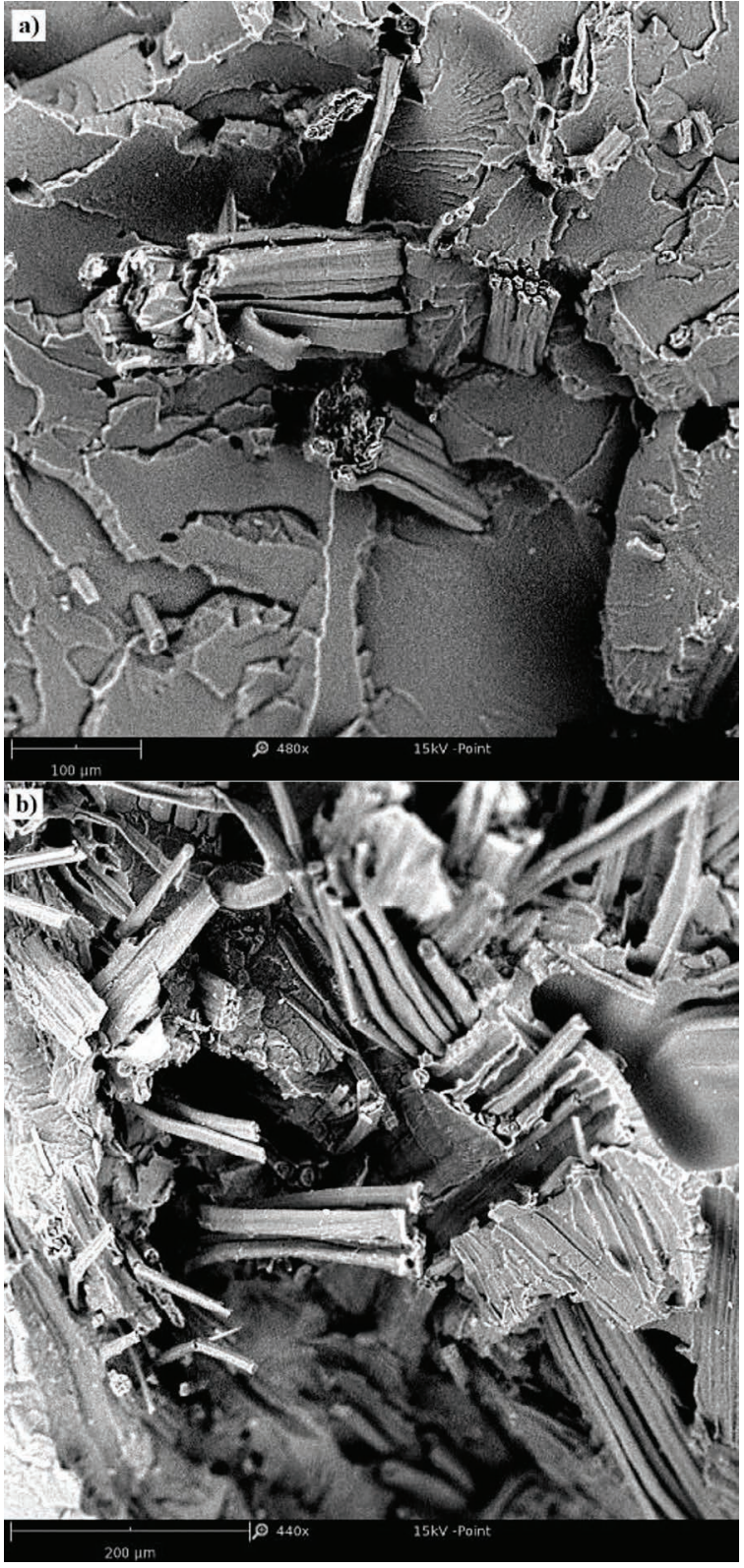

Figure 15. Morphology of the specimen with 4\% linen fiber content a) before degradation b) after degradation

obtain a fully degradable biocomposite. However, it is necessary to verify the amount of added fibers and the method of processing the composites so that the selected properties, especially mechanical ones, was satisfactory.

\section{Acknowledgments}

The article prepared as part of the project financed by the Polish National Agency for Academic Exchange no. PPN/ BIL/2018/1/00048/U/00001. 


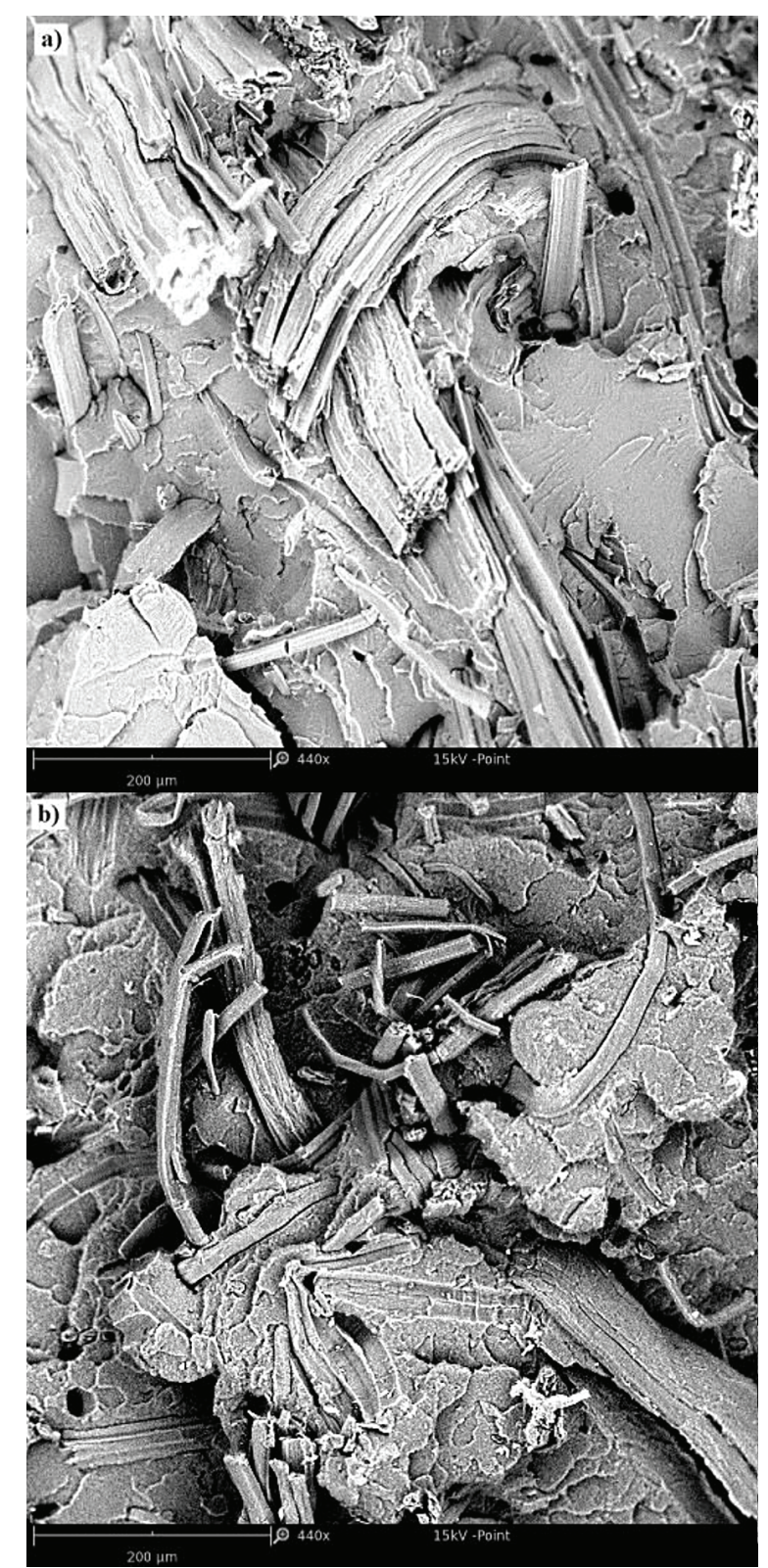

Figure 16. Morphology of the specimen with 5\% linen fiber content: a) before degradation b) after degradation

\section{REFERENCES}

1. Alam F., Varadarajan K.M., Kumar S.: 3D printed polylactic acid nanocomposite scaffolds for tissue engineering applications, Polymer Testing 81, 2020, 106203-106212.

2. Aravind Raj S., Muthukumaran E., Jayakrishna K.: A case study of 3D printed PLA and its mechanical properties, Materials Today: Proceedings 5, 2018, 11219-11226.

3. Basu, A.; Nazarkovsky M., Ghadi R., Khan W., Domb A.J.: Poly (lactic acid)-based nanocomposites, Polymer Advanced Technologies 28, 2017, 919-930.
4. Bernava A. and Reihmane S. Influence of modification methods on colour properties of a linen fabric dyed with direct dyes. Proceedings of the Estonian Academy of Sciences, 2(67), 2018, 131-137.

5. Castro-Aguirre E., Iñiguez-Franco F., Samsudin H., Fang X. and Auras R. Poly(lactic acid)-Mass production, processing, industrial applications, and end of life. Advanced Drug Delivery Reviews 107, 2016, 333-366.

6. Eutionnat-Diffo P.A., Chen Y., Guan J. et al.: Stress, strain and deformation of poly-lactic acid filament deposited onto polyethylene terephthalate woven fabric through 3D printing proces, Scientific Reports 9, 2019, 14333-14351.

7. Farah S., Anderson D. G., Langer R.: Physical and mechanical properties of PLA, and their functions in widespread applications, Advanced Drug Delivery Reviews 107, 2016, 367-392.

8. Głogowska K., Majewski Ł., Garbacz T. and TorŚwiątek A. The effect of ageing on selected properties of polylactide modified with blowing agents. Advances in Science and Technology Research Journal, 4(13), 2019, 204-213

9. Gołębiewski J., Gibas E. and Malinowski R.: Wybrane polimery biodegradowalne - otrzymywanie, właściwości, zastosowanie. Polimery, 11-12(53), 2008, 799-807.

10. Hakkarainen M. Aliphatic Polyesters: Abiotic and biotic degradation and degradation products. Degradable aliphatic polyesters. Advances in Polymer Science, vol 157. Springer, 2002

11. ISO 105-J03:2009 - Textiles -- Tests for colour fastness - Part J03. Calculation of colour differences.

12. Kaczmar J.W., Pach J. and Kozłowski R.: Wykorzystanie włókien naturalnych jako napełniaczy kompozytów polimerowych. Polimery, 10(51), 2006, 29-33.

13. Kaseem M.: Poly(Lactic Acid) Composites, Materials 12, 2019, 3586-3587.

14. Koronis G., Silva A. and Fontul M.: Green composites: A review of adequate materials for automotive applications. Composites Part B, 44, 2013, 120-127.

15. Kulma A., Zuk M., Long S.H., Qiu C.S., Wang Y.F., Jankauskiene S., Preisner M., Kostyn K. and Szopa J.: Biotechnology of fibrous flax in Europe and China. Ind. Crops and Prod., 68, 2015, 50-59.

16. Langer R., Basu A., Domb A.J.: Polylactide (PLA) Based Biopolymers, Advanced Drug Delivery Reviews 107, 2016, 1-2.

17. Majid Jamshidian, Elmira Arab Tehrany, Muhammad Imran, Muriel Jacquot, and St'ephane Desobry.: Poly-lactic acid: production, applications, nanocomposites, and release studies, Comprehensive Reviews in Food Science and Food Safety 9, 2010, 552-571. 
18. Malinowski R.: Poli(kwas mlekowy) - jeden z głównych przedstawicieli biotworzyw. Biotworzywa, 1, 2015, 35-38.

19. Moghaddam M. A., Stloukal P., Kucharczyk P., Tor-Swiatek A, Garbacz T., Pummerova M., Klepka T. and Sedlařík V. Microcellular antibacterial polylactide - based systems prepared by additive extrusion with ALUM. Polymers for Advanced Technologies, 8(30), 2019, 2100-2108.

20. Pil L., Bensadoun F., Pariset J. and Verposet I.: Why are designers fascinated by flax and hemp fibre composites? Composites Part A, 83, 2016, 193-205.

21. Rasal R. M., Janorkar A.V.,. Hirt D.E: Poly(lactic acid) modifications, Progress in Polymer Science 35, 2010, 338-356.

22. Rigolin T.R., Costa L.C., Chinelatto M.A. et al.: Chemical modification of poly(lactic acid) and its use as matrix in poly(lactic acid) poly(butylene adipate-co-terephthalate) blends, Polymer Testing 63, 2017, 542-549.
23. Savioli Lopes M., Jardinib A. L., Maciel Filhoa R.: Poly (lactic acid) production for tissue engineering applications. Procedia Engineering 42, 2012, 1402-1413.

24. Was-Gubala J. and Machnowski W.: Application of Raman spectroscopy for differentiation among cotton and viscose fibers dyed with several dye classes, Spectroscopy Letters, 7 (47), 2014, 527-535. DOI: $10.1080 / 00387010.2013 .820760$

25. Yan L., Chouw N. and Jayaraman K.: Flax fibre and its composites - A review. Composites Part B 56, 2014, 296-317.

26. Yue Qi, Hui-Ling Ma, Zhong-He Du, Bo Yang, Jing Wu, Rui Wang, and Xiu-Qin Zhang: Hydrophilic and Antibacterial Modification of Poly(lactic acid) Films by $\gamma$-ray Irradiation, ACS Omega 25 , 2019, 21439-21445.

27. Żenkiewicz M. and Richert J.: Synteza, właściwości i zastosowanie polilaktydu, Przetwórstwo tworzyw, 5, 2009, 192-199. 